\title{
ANALISIS TINGKAT SEISMISITAS DAN TINGKAT KERAPUHAN BATUAN DI MALUKU UTARA
}

\author{
Vienda Gaby Lumintang ${ }^{1)}$, Guntur Pasau ${ }^{1)}$, Seni Herlina J. Tongkukut ${ }^{1)}$ \\ ${ }^{1)}$ Jurusan Fisika FMIPA Universitas Sam Ratulangi Manado \\ e-mail: blue_kaka7@yahoo.co.id; pasaujunior@gmail.com; sjtongkukut@yahoo.com
}

\begin{abstract}
ABSTRAK
Telah dilakukan penelitian untuk menentukan tingkat seismisitas dan tingkat kerapuhan batuan melalui perhitungan nilai a dan b secara spasial di Maluku Utara menggunakan katalog gempa ANSS tahun 1963-2015 dengan metode maksimum likelihood, menghitung kemungkinan waktu terjadinya kembali gempa bumi merusak secara spasial, serta untuk menenentukan daerah-daerah yang sangat rawan berpotensi gempa merusak di wilayah Maluku Utara. Perhitungan nilai a dan $b$ dari data ANSS untuk wilayah Maluku Utara menunjukkan besar nilai $b$ adalah berkisar pada 0,75-1,5 dan nilai a adalah berkisar pada 6,5-10. Periode ulang gempa bumi untuk wilayah Maluku Utara dengan magnitude $M w=6,5$ adalah 3-19 tahun, gempa dengan magnitude $M w=7$ adalah 5-52 tahun, dan gempa dengan magnitude $M w=7,5$ adalah 15-140 tahun. Daerah-daerah yang berpotensi mengalami gempa bumi merusak adalah wilayah Laut Maluku, Ternate, Tidore, sebagian wilayah Kabupaten Halmahera Utara dan Barat, Pulau Kasiruta dan Pulau Obi.
\end{abstract}

Kata kunci: nilai-b, seismisitas, maximum likelihood

\section{ANALYSIS OF SEISMICITY LEVEL AND ROCKS FRAGILITY LEVEL IN NORTH MALUKU}

\begin{abstract}
A research has ben conducted to determine the seismicity level and rocks fragility level through spatially calculation of a value and $b$ value in North Maluku using ANSS earthquake catalog of years 1963-2015 with maximum likelihood method, spatially calculate possible time of destructive earthquake recurrence, and to determine areas that highly prone to potentially destructive earthquake in North Maluku. A value and b value calculation of ANSS data of North Maluku region shows that $\mathrm{b}$ value is in the range of 0.75-1.5 and a value is in the range of 6.5-10. Earthquake repetition period of North Maluku region based on ANSS data with magnitude $M w=$ 6.5 is 3-19 years, for earthquake with magnitude $M w=7$ is 5-52 years and for earthquake with magnitude $M w=7.5$ is $15-140$ years. Areas that potentially have destructive earthquake is Molucca Sea region, Ternate, Tidore, parts of North and West Halmahera District, Kasiruta Island and Obi Island.
\end{abstract}

Keywords: b value, seismicity, maximum likelihood

\section{PENDAHULUAN}

Gempa bumi adalah bergteranya permukaan tanah karena pelepasan energi secara tiba-tiba akibat dari pecah/slip-nya massa batuan di lapisan kerak bumi (Pawirodikromo, 2012). Sekitar $90 \%$ dari semua gempa bumi yang terjadi di bumi adalah hasil dari peristiwa tektonik, terutama gerakan pada daerah fault. Sisanya $10 \%$ berhubungan dengan vulkanisme, runtuhnya rongga bawah tanah, atau akibat buatan manusia (Lowrie, 2007).

Gempa bumi tektonik adalah jenis gempa bumi yang disebabkan oleh pergeseran lempeng tektonik. Gempa ini terjadi karena besarnya tenaga yang dihasilkan akibat adanya tekanan antar lempeng dalam perut bumi (Hartuti, 2009). 
Indonesia telah sering mengalami gempa bumi. Hal ini dikarenakan letak Indonesia yang berada pada pertemuan tiga lempeng besar dunia. Kepulauan Indonesia yang merupakan bagian dari lempeng Eurasia didorong oleh lempeng Indo-Australia dari sebelah selatan ke arah timur, sedangkan dari arah timur didorong oleh lempeng Pasifik ke arah barat. Selain itu terdapat pula satu lempeng mikro yaitu lempeng Filipina yang juga mendorong ke arah barat. Hal ini menyebabkan wilayah Indonesia sebagai salah satu wilayah yang sangat rawan terhadap gempa bumi.

Salah satu wilayah di Indonesia yang rawan gempa bumi adalah wilayah Maluku Utara. Propinsi Maluku Utara berbatasan dengan Samudera Pasifik di sebelah utara dan timur, Laut Seram di selatan dan Pulau Sulawesi di barat. Secara tektonik wilayah ini dipengaruhi oleh subduksi lempeng Filipina di utara hingga ke timur, sesar Sorong dan Sula di selatan, dan subduksi ganda lempeng Laut Maluku di sebelah barat. (Tim Revisi Peta Gempa 2010, 2010)

Pada 15 November 2014, wilayah ini diguncang gempa sebesar 7,3 Skala Richter menurut analisis Badan Meteorologi Klimatologi dan Geofisika dengan kedalaman hiposenter $48 \mathrm{~km}$ di Laut Maluku. Goncangan gempa bumi ini dirasakan cukup kuat oleh warga masyarakat di wilayah Sulawesi Utara dan Maluku Utara. Gempa tersebut sempat menimbulkan tsunami kecil setinggi 0,09 meter di Jailolo, 0,03 meter di Manado dan 0,01 meter di Tobelo. (Daryono, 2014)

Penelitian ini dilakukan untuk menentukan tingkat seismisitas dan tingkat kerapuhan batuan di Maluku Utara melalui perhitungan nilai a-b secara spasial dengan menggunakan katalog gempa ANSS, menghitung kemungkinan waktu terjadinya kembali gempa bumi merusak secara spasial, serta menentukan daerah-daerah yang sangat rawan berpotensi mengalami gempa merusak.

\section{TINJAUAN PUSTAKA}

\section{Kondisi Tektonik Maluku Utara}

Wilayah Maluku Utara terdiri atas 353 pulau dengan luas kira-kira $32.000 \mathrm{~km}^{3}$. Secara umum struktur fisiografi wilayah Maluku Utara terbentuk dari zona pertemuan dua sistem bentang alam yaitu Sistem
Bentang Alam Sangihe dan Sistem Bentang Alam Ternate dengan batasnya adalah Cekungan Celebes barat dan Cekungan Halmahera di timur.

Lempeng Laut Maluku, yaitu sebuah lempeng laut kecil mengalami tumbukan ke Palung Sangihe di bawah busur Sangihe di barat dan ke arah timur di bawah Halmahera, sedangkan di sebelah selatannya terikat oleh patahan Sorong. Menurut Kertapati (2006), dua zona penunjaman yang berlawanan arah ini membentuk kemiringan ganda yang tidak simetris. Zona Benioff dari Lempeng Maluku Utara menerus hingga kedalaman 600 kilometer, sedangkan di bawah busur Halmahera, zona Benioff relatif dangkal (300 kilometer). Subduksi ganda ini terbentuk akibat tekanan Lempeng laut Filipina dari timur di zona Halmahera. Sementara dari barat, Lempeng Sangihe mendorong ke timur.

\section{Distribusi Frekuensi Magnitudo dan Maximum Likelihood}

Relasi antara frekuensi dan magnitudo oleh Gutenberg-Richter dinyatakan dalam suatu hubungan sebagai:

$\log \mathrm{N}=\mathrm{a}-\mathrm{bM}$

dimana

$N=$ jumlah gempa bumi dengan

magnitude

$$
\mathrm{M} \geq \mathrm{m}
$$

$M=$ magnitudo gempa

$a=$ konstanta parameter sesimik yang bergantung pada periode

pengamataan dan tingkat

kegempaan suatu wilayah

$b=$ konstanta parameter tektonik yang bergantung pada karakter

tektonik dan tingkat stress

atau struktur material suatu

wilayah

Nilai-b dapat diperkirakan dengan cara statistik, salah satunya yang dikemukakan oleh Utsu (1965) yang dikenal dengan metode estimasi maksimum likelihood dengan persamaan:

$b=\frac{\log e}{M-M_{0}}$

dimana:

$$
\begin{aligned}
& M=\text { rata-rata magnitudo } \\
& M_{0}=\text { nilai minimum magnitudo } \\
& \log e=0,4343
\end{aligned}
$$

Bersesuaian dengan nilai-a yang diperhitungkan dari hubungan frekuensi kumulatif untuk $\mathrm{M}>\mathrm{M}_{0}$ adalah: 
$a=\log N\left(M>M_{0}\right)+\log (b \ln 10)+$

$M_{0} b$..(3)

dengan:

$N=$ jumlah kumulatif data yang digunakan

$b=$ kemiringan garis lurus yang dinyatakan oleh persamaan empiris Gutenberg-Richter.

Jumlah gempa per tahun secara teoritis dihitng dengan membagi nilai-a dengan periode observasi $(\mathrm{T})$ yaitu $\mathrm{a}_{1}=\mathrm{a} / \log \mathrm{T}$, dimana $\mathrm{T}$ adalah tahun. Adapun indeks seismisitas atau jumlah frekuensi kumulatf gempa pertahun adalah:

$$
N_{1}(M)=10^{a_{1}-b M}
$$

Dengan demikian dapat diformulasikan kemungkinan terjadinya satu kali atau lebih gempa bumi dengan magnitudo lebih besar dari $\mathrm{M}$ dalam periode $\mathrm{T}$ sebagai:

$$
P(M, T)=\left(1-e^{-N(M) T}\right)
$$

Dengan diperoleh $\mathrm{N}_{1}(\mathrm{M})$ maka dapat dihitung kemungkinan waktu terjadinya kembali gempa bumi merusak, yaitu:

$$
\theta=\frac{1}{N_{1}(M)} \text { tahun }
$$

Dengan $\theta$ adalah periode berulang.

\section{METODE PENELITIAN}

Langkah-langkah dalam penelitian ini sebagai berikut:

1. Studi literatur dengan menelaah pustaka yang berhubungan dan mendukung penelitian ini.

2. Data gempa diambil dari katalog gempa ANSS periode tahun 19632015. Data tersebut meliputi wilayah Maluku Utara pada $124^{\circ} \mathrm{BT}-130^{\circ} \mathrm{BT}$ dan $3^{\circ} \mathrm{LU}-3^{\circ} \mathrm{LS}$ dengan kekuatan gempa dipilih pada magnitudo minimum $\geq 4$ dan kedalaman maksimum $700 \mathrm{~km}$.

3. Pengolahan data gempa.

a. Skala magnitudo dari katalog gempa dikonversi menjadi $M w$ dengan menggunakan persamaan empiris hubungan antara beberapa magnitudo gempa yang diusulkan oleh Scrodilis (2006). Secara matematis hubungan antara $m_{b}$ dan $M_{w}$ sebagai berikut:

$$
M_{w}=0,85 m_{b}+1,03 \quad 3,5 \leq
$$

$m_{b} \leq 6,2 . .(7)$

Sedangkam hubungan empiris antara $M s$ dan $M_{w}$ adalah:

$$
\begin{array}{ccc}
M_{w}=0,67 M_{s}+2,073 & 0 \leq & M_{s} \\
\leq 6,1 \ldots(8) & & \\
M_{w}=0,99 M_{s}+0,086 & 2 \leq & M_{s}
\end{array}
$$

$\leq 8,2 \ldots$. (9)

b. Pemilahan data gempa untuk menentukan gempa utama dengan menggunakan kriteria rentang waktu dan rentang jarak sesuai metode Gardner \& Knopoff (1974).

c. Penentuan Kelengkapan Magnitudo (Mc)

d. Perhitungan nilai a-b secara spasial menggunakan metode maximum likelihood yang memberikan hasil yang lebih stabil karena memodelkan kemiringan garis yaitu dari kemiringan nilai tengah magnitude fungsi distribusi Gaussian (Pasau dan Tanauma, 2011). Wilayah penelitian dibagi menjadi 4 wilayah yaitu pada $124^{\circ} \mathrm{BT}-127^{\circ} \mathrm{BT}$ dan $0^{\circ}-3^{\circ} \mathrm{LU}$, $127^{\circ} \mathrm{BT}-130^{\circ} \mathrm{BT}$ dan $0^{\circ}-3^{\circ} \mathrm{LU}$, $124^{\circ} \mathrm{BT}-127^{\circ} \mathrm{BT}$ dan $0^{\circ}-3^{\circ} \mathrm{LS}$, $127^{\circ} \mathrm{BT}-130^{\circ} \mathrm{BT}$ dan $0^{\circ}-3^{\circ} \mathrm{LS}$ dengan ukuran grid horisontal $0,1^{\circ} \times 0,1^{\circ}$.

e. Perhitungan kemungkinan waktu terjadinya kembali gempa bumi merusak secara spasial berdasarkan hasil perhitungan nilai a-b.

4. Penentuan daerah-daerah yang berpotensi mengalami gempa bumi merusak dari analisis hasil perhitungan nilai a-b dan kemungkinan waktu terjadinya kembali gempa bumi merusak secara spasial.

\section{HASIL DAN PEMBAHASAN}

Terdapat 8.284 data gempa dari katalog gempa ANSS dengan $\mathrm{Mw} \geq 4$ pada kedalaman $<700 \mathrm{~km}$. Tersisa 1.243 data gempa utama setelah proses pemilahan data gempa dengan metode Gardner \& Knopoff (1974). Dan nilai Mc yang diperoleh pada penelitian ini adalah 4,9.

Hasil perhitungan nilai-b secara spasial diberikan melalui pemetaan di bawah ini: 


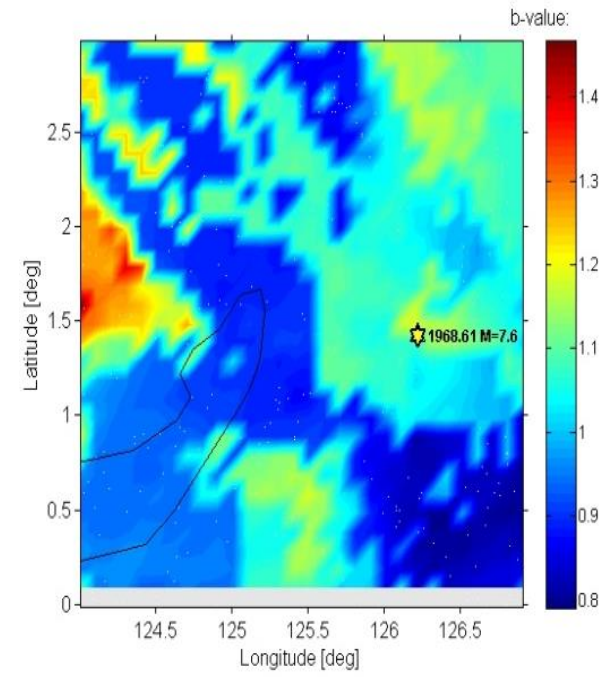

(a)

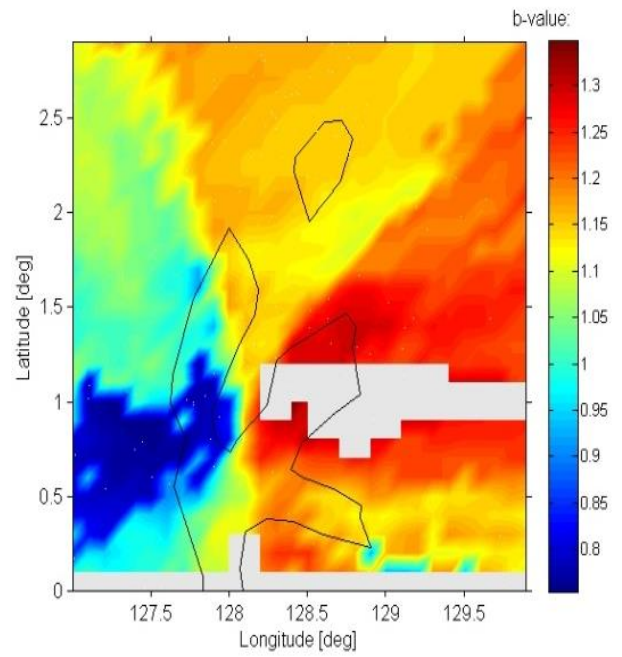

(b)

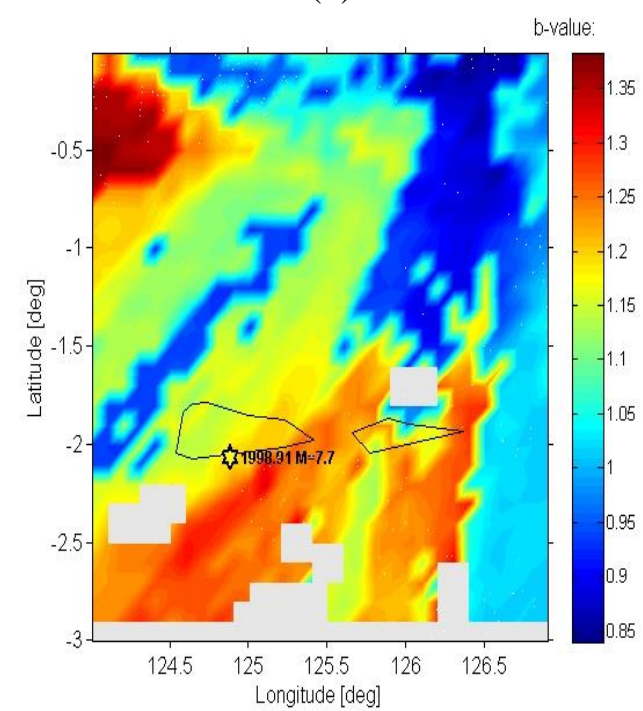

(c)

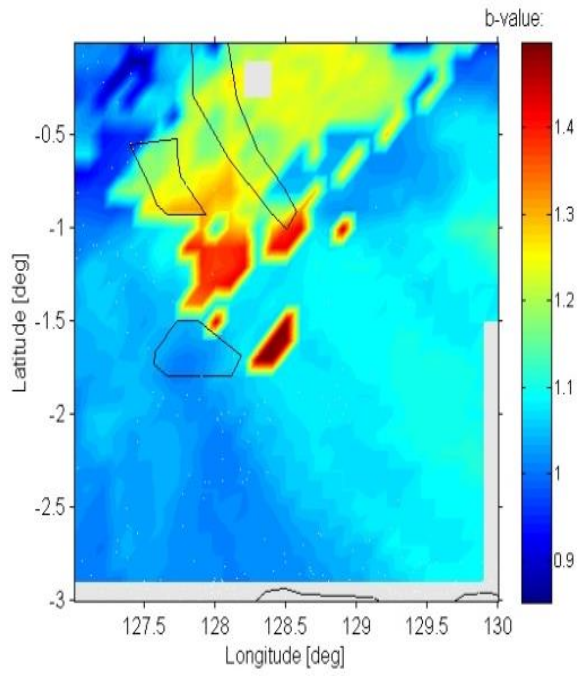

(d)

Gambar 2. Hasil Perhitungan nilai-b Secara Spasial (a) Wilayah Pertama, (b) Wilayah Kedua, (c) Wilayah Ketiga, (d) Wilayah Keempat

Secara menyeluruh, nilai-b yang ditunjukkan oleh wilayah Maluku Utara dari keempat pembagian wilayah penelitian berkisar pada 0,75-1,5. Wilayah dengan nilaib terendah, berkisar pada 0,75-1,1 berada pada wilayah Laut Maluku, Ternate, Tidore, Pulau Kasiruta dan Pulau Obi yang ditunjukkan dengan warna biru tua. Sedangkan wilayah lainnya memiliki nilai-b yang lebih tinggi.

Pada perhitungan nilai-a secara spasial, wilayah Maluku Utara memiliki nilai-a dengan kisaran 6,5-10. Wilayahwilayah dengan nilai-a yang tinggi menunjukkan tingkat seismisitas yang tinggi.

Wilayah-wilayah dengan nilai-a yang tinggi, juga merupakan wilayah-wilayah dengan nilai $b$ yang tinggi. Hal ini serupa dengan pernyataan Rohadi (2009), yaitu pola distribusi nilai-b dan nilai-a memiliki kesesuaian dimana wilayah dengan nilai-b tinggi bersesuaian dengan nilai-a yang tinggi.

Dari hasil perhitungan periode ulang gempa bumi, prediksi terjadinya ulang gempa dengan $M w=6,5$ adalah 3-19 tahun, pada gempa dengan $M w=7$ adalah 5-52 tahun, dan pada gempa dengan $M w=7,5$ adalah 15140 tahun.

wilayah-wilayah dengan periode ulang gempa tercepat umumnya adalah wilayah-wilayah dengan nilai a-b terendah, seperti pada wilayah Laut Maluku, Ternate, Tidore, sebagian wilayah Kabupaten 
Halmahera Utara dan Barat, Pulau Kasiruta dan Pulau Obi. Hal ini menunjukkan bahwa wilayah-wilayah tersebut lebih berpotensi untuk terjadi gempa dengan magnitude besar.

\section{KESIMPULAN}

Dari hasil penelitian didapati bahwa wilayah Maluku Utara sebelah barat merupakan daerah dengan tingkat kerapuhan batuan dan tingkat seismisitas lebih rendah dibandingkan wilayah Maluku Utara sebelah timur, yaitu dengan kisaran 0,8-0,95. Berdasarkan analisis tingkat seismisitas dan tingkat kerapuhan batuan di wilayah Maluku Utara, maka daerah-daerah yang berpotensi mengalami gempa bumi merusak adalah wilayah Laut Maluku, Ternate, Tidore, sebagian wilayah Kabupaten Halmahera Utara dan Barat, Pulau Kasiruta dan Pulau Obi.

\section{DAFTAR PUSTAKA}

Kertapati, E. 2006. Aktifitas Gempa Bumi di Indonesia, Perspektif Regional pada Karakteristik Gempa Bumi Merusak. Badan Geologi, Bandung.
Lowrie, William. 2007. Fundamental of Geophysics. Cambridge University Press, New York.

Pasau, G., dan A. Tanauma. 2011. Pemodelan Sumber Gempa di Wilayah Sulawesi Utara Sebagai Upaya Mitigasi Bencana Gempa Bumi. Journal science of MIPA. 7:1-5

Pawirodikromo, Widodo. 2012. Seismologi Teknik \& Sejarah Kegempaan. Pustaka Pelajar, Yogyakarta.

Rohadi, Supriyanto. 2009. Distribusi Spasial dan Temporal Seismotektonik Wilayah Subduksi Jawa. Megasains 1(4):180-188

Scrodilis, E.M. (2006). Empirical Global Relations Converting $\mathrm{Ms}$ and $\mathrm{Mb}$ to Moment Magnitudo, Journal of Seismology, 10:225-236

Tim Revisi Peta Gempa Indonsia. 2010. Ringkasan Hasil Studi Tim Revisi Peta Gempa Indonesia 2010. Bandung.

Wandono et al. 2004. Analisis Hubungan Frekwensi-Magnitudo Gempa Bumi di Bali dan Sekitarnya. Jurnal Matematika dan Sains. 9(3):273-277 